\title{
RANCANG BANGUN SISTEM KONTROL OTOMATIS PERALATAN LISTRIK BERBASIS ARDUINO UNO
}

\author{
Debbi Ayu Shintya Dewi ${ }^{1 *}$, Handini Arga Damar Rani ${ }^{2}$ \\ Universitas Ivet ${ }^{1}$, Universitas Ivet ${ }^{2}$ \\ *debbyayu891@gmail.com
}

Diterima: Mei 2021. Disetujui: Juni 2021. Dipublikasikan: Juni 2021

\begin{abstract}
ABSTRAK
Sistem kontro1/kendali merupakan sebuah inovasi yang hadir karena ketertarikan manusia untuk menciptakan sebuah alat lainnya sekaligus pada sebuah sistem di satu titik. Dengan berkembangnya teknologi, Arduino menjadi sangat populer dikalangan mahasiswa dan pelajar saat ini. Mereka mengembangkan arduino dengan bootloader dan software yang user friendly. sehingga menghasilkan sebuah board mikrokontroller yang bersifat open source yang bisa dipelajari dan dikembangkan oleh mahaswa, pelajar, profesional, pemula dan penggemar elektronika maupun robotika diseluruh dunia. Tujuan penelitian ini 1) Mempermudah penggunaan sistem kontrol ini untuk orang yang mempunyai kecacatan fisik seperti lumpuh dan segala kecacatan fisik untuk bergerak. 2) Alat sistem kendali peralatan listrik ini bertujuan untuk mempermudah kita, karena tidak perlu lagi berpindah tempat hanya untuk menyalakan dan mematikan suatu peralatan listrik. Hasil dari penelitian ini adalah Sistem kontrol otomatis peralatan listrik yang telah dirancang mampu mengontrol penggunaan peralatan melalui smartphone/android. Modul Bluetooth HC-05 dapat digunakan sebagai alternative remote untuk menghidupkan relay, sehingga dapat digunakan untuk menghidupkan perangkat listrik.
\end{abstract}

Kata kunci: media pembelajaran, ketuntasan belajar, kemandirian belajar, perangkat pembelajaran

\section{ABSTRACT}

Control system is an innovation that is present because of human interest to create another tool at once on a system at one point. With the development of technology, Arduino became very popular among students and students today. They developed arduino with bootloader and userfriendly software. This producing an open source control board that can be learned and developed by students, students, professionals, beginners, and enthusiasts of electronics and robotics around the world. The purpose of this study is 1) Make it easier to use this control system for people with physical disabilities such as paralysis and any physical disabilities to move around.

2) This electrical equipment control system tool aims to make it easier for us, because there is no need to move around just to turn on and off an electrical equipment. The result of this study is an automatic control system of electrical equipment that has been designed to control the use of electrical equipment through smartphones / androids. The app can run well with trials on smartphones/android. Modul Bluetooth HC-05 can be used as an alternative remote to turn on the relay, so it can be used to turn on the power device.

Keywords: Control System, Electrical Equipment, Arduino, Smartphone

\section{PENDAHULUAN}

Perkembangan ilmu pengetahuan dan teknologi membawa dampak positif dalam kehidupan manusia untuk berlomba memanfaatkan informasi sesuai dengan tujuannya. Adapun sistem kontrol rumah pintar memungkinkan manusia mengendalikan perangkat listrik rumah 
mereka seperti TV, kipas angin, dan lampu hanya dengan menggunakan perintah tombol dari smartphone/android tanpa perlu bergerak atau berpindah tempat untuk menyalakan atau mematikan suatu peralatan listrik.

Sistem kontrol/kendali merupakan sebuah inovasi yang hadir karena ketertarikan manusia untuk menciptakan sebuah alat lainnya sekaligus pada sebuah sistem di satu titik. Banyaknya peralatan terutama peralatan elektronika yang harus dikendalikan atau luasnya suatu wilayah (komplek, gedung) pada rumah atau pabrik membuat sistem kontrol/kendali menjadi pilihan untuk mendapatkan sebuah kepraktisan dalam pengaksesan perangkat elektronika yang letaknya berbeda dengan cepat pada sebuah titik pusat tanpa harus berpindah dari satu tempat ketempat lain.

Sistem ini dapat membantu manusia dalam pengontrolan peralatan listrikrumah sehari-hari, seperti lampu, kipas angin, pompa air dan lain-lain.Karena komponen tersebut komponen penting yang berada pada bagian rumah.Sehingga dengan adanya alat ini dapat membantu pengontrolan listrik dengan memberikan perintah tombol terhadap sistem. Alat ini sangat berguna bagi pemilik rumah yang memiliki kekurangan dalam hal fisik seperti lumpuh dan segala hal kecacatan fisik untuk bergerak.

\section{METODE PENELITIAN}

\section{A. Jenis Penelitian}

National Science Board dalam "Research and Development: Essential Foundation For U.S Competitiviness in A Global Economy" dalam Nusa Putra (2013: 70) Pengembangan didefinisikan sebagai aplikasi sistematis dan pengetahuan atau pemahaman, diarahkan pada produksi bahan yang bermanfaat, perangkat, dan sistem atau metode dan termasuk desain, pengembangan dan peningkatan prioritas serta proses baru untuk memenuhi persyaratan tertentu.
Dengan demikian penelitian ini menggunakan metode Research and Development. Penelitian ini bertujuan untuk memudahkan manusia dalam menggunakan peralatan listrik seperti lampu, kipas angin dan lain-lain. Sistem control pada produk ini menggunakan smartphone/android yang dihubungkan menggunakan Arduino uno.

\section{B. Prosedur Pengembangan}

Prosedur pengembangan pada penelitian ini menggunakan model waterfall.Menurut (Pressman, 2015:42), model waterfall adalah model klasik yang bersifat sistematis, berurutan dalam membangun software. Nama model ini sebenarnya adalah "Linear Sequential Model". Model ini sering disebut juga dengan "classic life cycle" atau metode waterfall. Model ini melakukan pendekatan secara sistematis dan berurutan. Disebut dengan waterfall karena tahap demi tahap yang dilalui harus menunggu selesainya tahap sebelumnya dan berjalan berurutan.

Fase-fase dalam Waterfall Model menurut referensi Pressman:

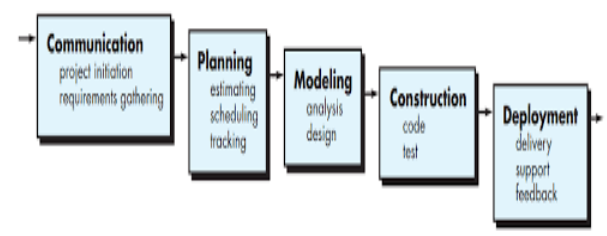

Gambar 3.1.Waterfall Pressman (Pressman, 2015: 42)

1. Communication (Project Intitation \& Requirements Gathering)

Pada tahap pertama ini dilakukan analisis permasalahan yang dihadapi yaitu pengontrolan listrik pada rumah supaya mudah dikontrol dan keamanan terjaga dengan baik.

2. Planning (Estimatting, Scheduling, Tracking) 
Pada tahap ini penulis membuat perencanaan desain untuk pengontrolan dan pemrograman.

3. Modeling (Analysis \& Design)

Tahapan ini adalah tahap perancangan dan permodelan arsitektur sistem. Tahap desain dalam penelitian ini meliputi desain flowchart untuk perancangan perangkat lunak, diagram blok sistem monitoring untuk perancangan perangkat keras, diagram wiring untuk perancangan komponen elektronika, dan desain antarmuka (user interface) untuk tampilan sistem pengontrolan.

4. Construction (Code \& Test)

Tahapan ini merupakan proses penerjemahan bentuk desain menjadi kode atau bentuk/bahasa yang dapat dibaca oleh mesin. Setelah pengkodean selesai, selanjutnya tahap pengujian. Pengujian yang dilakukan pada penelitian ini yaitu pengujian hardware dan software, serta pengujian pada aspek usability untuk mengevaluasi kualitas system. Proses pengujian usability menggunakan instrumen kuesioner yang sudah teruji validitas dan reliabilitasnya, yaitu USE Quistionnaire dari Arnold M. Lund yang akan diisi oleh pengguna.

5. Deployment (Delivery, Support, Feedback)

Tahapan ini merupakan tahapan implementasi software, pemeliharaan software secara berkala, perbaikan software, evaluasi software, dan pengembangan software berdasarkan umpan balik yang diberikan agar sistem dapat tetap berjalan dan berkembang sesuai dengan fungsinya. (Pressman, 2015:17). Pada penelitian ini, agar sistem mampu berjalan dengan baik kedepannya, maka perlu dilakukan pemeliharaan terhadap suatu sistem. Sehingga peneliti perlu memberikan petunjuk penggunaan dan perawatan yang harus dilakukan oleh pengguna untuk melakukan pemeliharaan terhadap sistem kontrol otomatis peralatan listrik pada lampu.

\section{Sumber Data atau Subjek Penelitian}

Sumber data dalam penelitian ini terdiri dari beberapa responden untuk pengujian perangkat lunak dan perangkat keras. Sugiyono (2015: 118) mengemukakan bahwa sampel adalah bagian dari jumlah dan karakteristik yang dimiliki oleh populasi. Pada penelitian ini pengambilan sample menggunakan teknik sampling jenuh.

Sampling jenuh adalah teknik penentuan sampel bila semua anggota populasi digunakan sebagai sampel. Hal ini sering dilakukan bila jumlah populasi relatif kecil, yakni kurang dari 3 orang (responden), atau penelitian yang ingin membuat generalisasi dengan kesalahan yang sangat kecil (Sugiyono, 2015: 124).

\section{E. Teknik Pengumpulan Data}

Teknik pengumpulan data adalah suatu langkah yang dinilai strategis dalam penelitian, karena mempunyai tujuan yang utama dalam memperoleh data, Sugiyono (2016:193). Dalam melakukan penelitian ini menggunakan beberapa teknik pengumpulan data antara lain:

1) Observasi

Observasi ini dilakukan dengan cara mengamati secara langsung sistem kontrol otomatis tersebut, agar memperoleh gambaran apa saja yang harus ada dalam sistem kontrol yang akan dibuat agar sistem dapat berfungsi lebih baik.

2) Kuesioner/angket

Kuesioner merupakan suatu teknik pengumpulan data yang dilakukan dengan cara memberikan pertanyaan-pertanyaan secara tertulis kepada responden. Teknik ini 
efektif jika peneliti telah mengetahui benar variable yang akan diukur serta keinginan yang diharapkan oleh responden dalam

penelitian.

\section{F. Instrument Penelitian}

Instrumen penelitian merupakan alat yang digunakan untuk mengumpulkan data pada suatu penelitian. Instrumen penelitian yang digunakan untuk menguji kualitas perangkat lunak dan perangkat keras ini yaitu menggunakan instrumen usability ISO 9126.

\section{G. Usability}

Instrumen yang digunakan dalam pengujian usability menggunakan kuesioner USE Quistionnaire dari Arnold M.Lund. USE Quistionnaire mempunyai 4 aspek yaitu usefullness (kegunaan), satisfaction (kepuasan), ease of use (mudah digunakan) dan ease of learning (mudah dimengerti). Menurut Sauro (2010) apabila kuesioner yang digunakan mempunyai pertanyaan yang banyak, maka disarankan menggunakan skala Likert. Skala Likert dengan skala 5 sering digunakan peneliti untuk mengukur tingkat kesuksesan dalam penelitian (Losby and Wetmore, 2012). Skala tersebut meliputi: sangat setuju (SS), setuju (S), ragu-ragu (RG), tidak setuju (TS), sangat tidak setuju (STS).

\section{HASIL DAN PEMBAHASAN}

Pada pengujian aspek usability peneliti menggunakan 3 (orang) responden yang merupakan peneliti utama yaitu 3 warga Desa Donglo di Kabupaten Blora terhadap peralatan listrik menggunakan Arduino uno. Hasil dari pengujian aspek usability pada sistem kontrol otomatis peralatan listrik berbasis Arduino uno dapat ditujukan pada tabel berikut.

Tabel 4.2. Hasil Perhitungan Usability

\begin{tabular}{llll} 
Jawaban & Jumlah & Skor & $\begin{array}{l}\text { Jumlah } \\
\text { Skor }\end{array}$ \\
\hline STS & 0 & 1 & 0 \\
\hline TS & 0 & 2 & 0 \\
\hline RR & 8 & 3 & 24 \\
\hline S & 41 & 4 & 164 \\
\hline SS & 41 & 5 & 205 \\
\hline Total & & & 393
\end{tabular}

Presentase pencapaian dapat dihitung menggunakan rumus:

Presentase Pencapaian $=\frac{\text { skor total }}{\text { skor maksimal }} \times 100 \%$

Skor Total = Nilai total yang

didapat dari jawaban responden

$\begin{array}{ll} & =393 \\ \text { Skor maksimal } & =\text { jumlah pernyataan }\end{array}$

$\times$ jumlah skor $\times 5$

$$
=30 \times 3 \times 5=450
$$

Presentase Pencapaian $=\frac{\mathbf{3 9 3}}{\mathbf{4 5 0}} \times 100 \%$

Berdasarkan hasil perhitungan di atas, maka hasil pengujian aspek usability terletak pada daerah Sangat Baik.Hal ini dapat dilihat pada tabel kriteria interprestasi skor.

Dari pengujian Usability yang telah dilakukan dengan menggunakan kuesioner USE Quistionnare dari Arnold M.Lund mendapatkan hasil presentase pencapaian yaitu $87,3 \%$. Presentase tersebut apabila dikonversi ke dalam skala kualitatif masuk dalam kategori Sangat Baik.Maka dapat disimpulkan bahwa sistem kontrol otomatis peralatan listrik ini sudah memenuhi aspek usability dan standar kualitas perangkat ISO.

Pada penelitian ini, hasil pengujian hipotesisnya yaitu perancangan sistem kontrol otomatis peralatan listrik yang penulis buat mampu berfungsi secara real time serta dapat mengefisiensikan pengguna yang telah dibuktikan pada hasil pengujian aspek usability berdasarkan penilaian dari responden. 


\section{PENUTUP}

\section{A. Simpulan}

Berdasarkan hasil implementasi dan pengujian perancangan sistem kontrol otomatis peralatan listrik, maka dapat diambil kesimpulan yaitu sebagai berikut:

1. Sistem kontrol otomatis peralatan listrik yang telah dirancang mampu mengontrol penggunaan peralatan listrik melalui smartphone/android. Aplikasi dapat berjalan dengan baik dengan uji coba pada smartphone/android. Modul Bluetooth HC-05 dapat digunakan sebagai alternative remote untuk menghidupkan relay, sehingga dapat digunakan untuk menghidupkan perangkat listrik. Bluetooth HC-05 merupakan Bluetooth generasi ke-2 dengan kecepatan modulasi 3 Mbps, frekuensi 2,4 $\mathrm{GHz}$, dan jarak maksimum $10 \mathrm{~m}$. Pengujian tingkat kualitas sistem kontrol otomatis peralatan listrik ini dilakukan dengan menggunakan standar ISO pada aspek usability. Presentasi yang diperoleh yaitu mencapai 87,3\% yang termasuk dalam kategori Sangat Baik berdasarkan dari tabel kriteria interprestasi skor.

2. Proses terhubungnya modul relay ke smartphone/android yaitu dengan membuat aplikasi smartswitchbLu yang telang dirancang melalui aplikasi MIT App Inventor.

\section{B. Saran}

Adapun saran yang dapat disampaikan penulis pada skripsi ini adalah:
1. Penataan instalasi kabel yang belum rapi membuat perancangan produk tidak rapi. Oleh karena itu, perancangan kabel harus dimaksimalkan lagi dengan menyambungkan kabel type A to type B disambungkan ke kabel yang terdapat pada fittingan lampu.

2. Dalam produk yang dibuat belum ada indicator LED sebagai tanda Standby, OFF, dan ON. 


\section{DAFTAR PUSTAKA}

Anggil Agusta, "Pengaruh Smartphone terhadap Mahasiswa," Jurnal Informatika No 1 (2017).

Faroqi, Adam dan Barikly Maulana. Aplikasi Multimedia Interaktif Pembelajaran membaca, menulis, menghitung (Calistung), Bandung: UIN Sunan Gunung Djati, 2014.

Pressman, R.S. 2015.Rekayasa Perangkat

Lunak: Pendekatan Praktisi Buku I. Yogyakarta: Andi.

V.W. Rumopa and D. Pembimbing, "Kontrol Penerangan Ruangan
Menggunakan Sensor Suara (Speech Recognition) Berbasis Android," 2015.

Arifin, Jauhari, dkk. 2016. Perancangan Murottal Otomatis Menggunakan Mikrokontroller Arduino Mega 2560. Media Infotama. Vol. 12 (1:8-98)

Williams. B.K. and Sawyer, S.C. (2011). Using Information Teknology: A Practical Introduction to Computers th

and Communications. (9 edition). New York: Mc.Graw.Hil. 